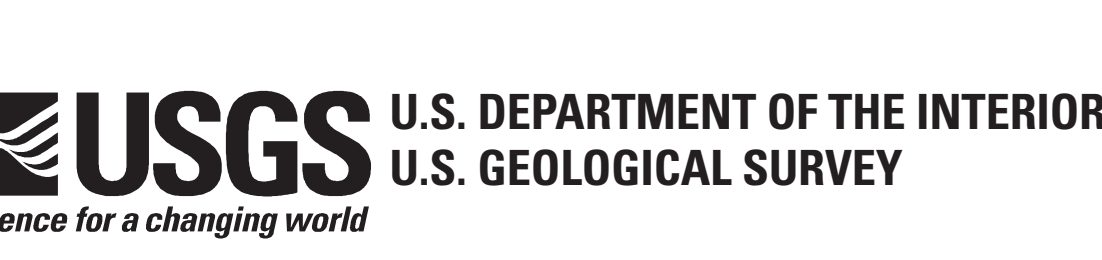

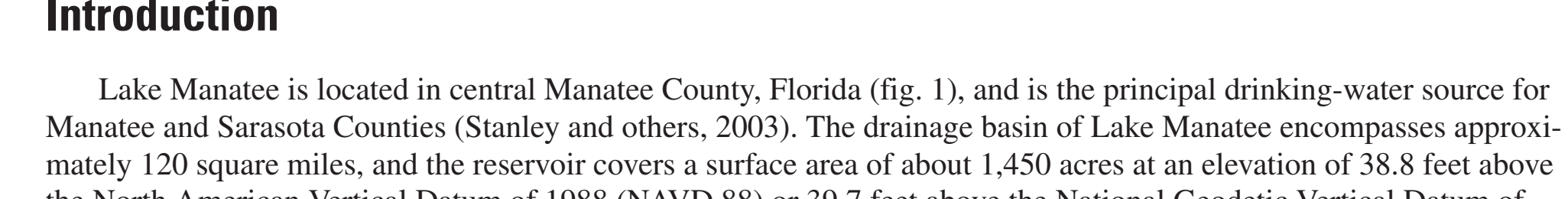

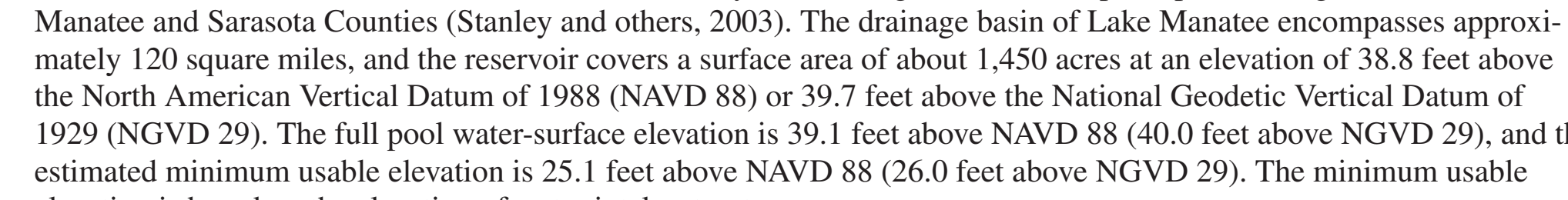

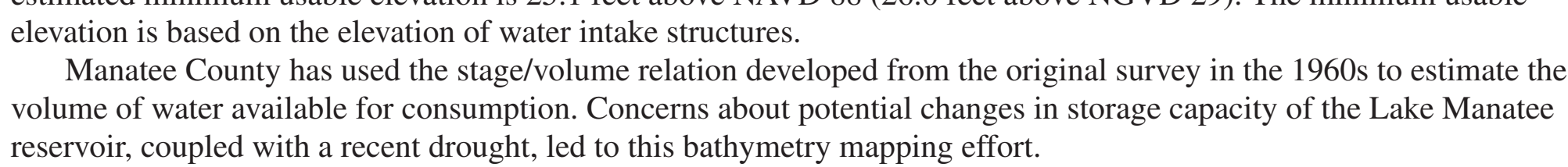

Methods

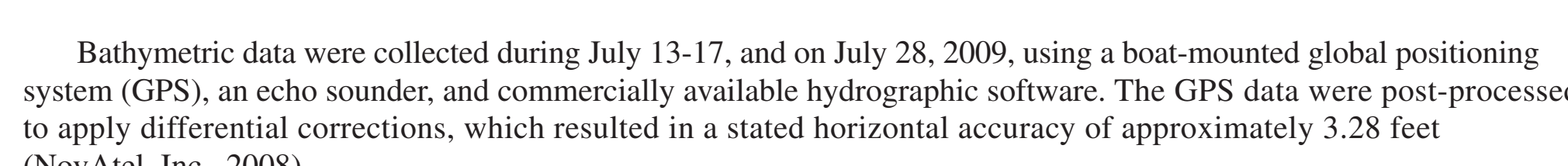

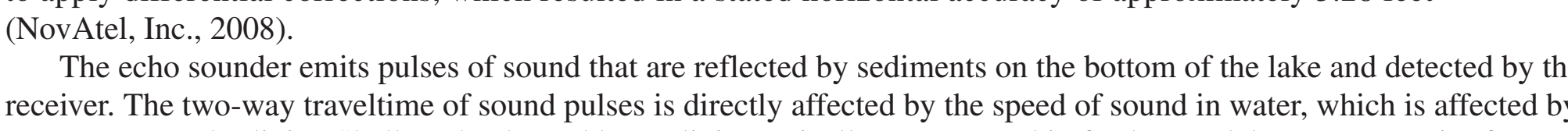

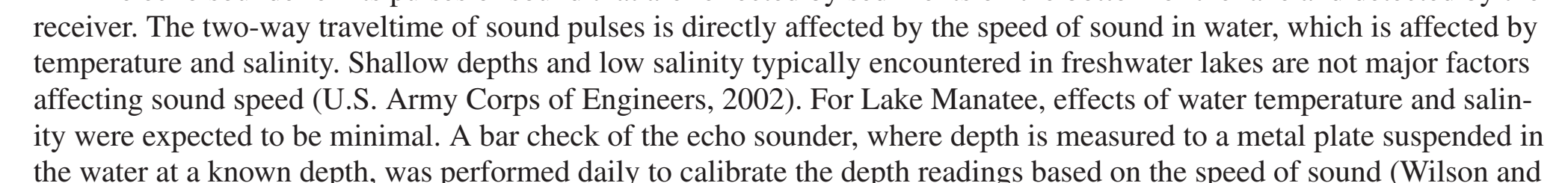

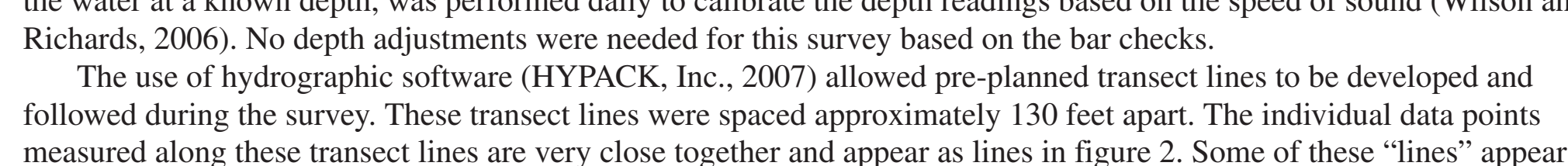

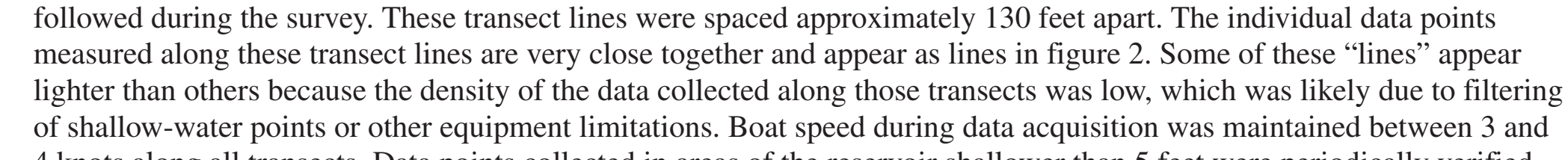

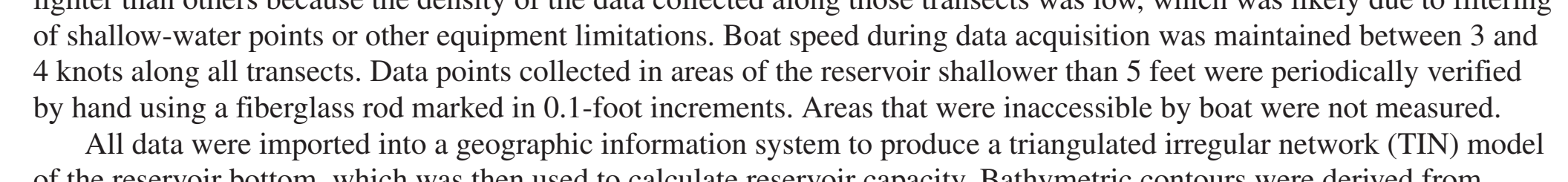

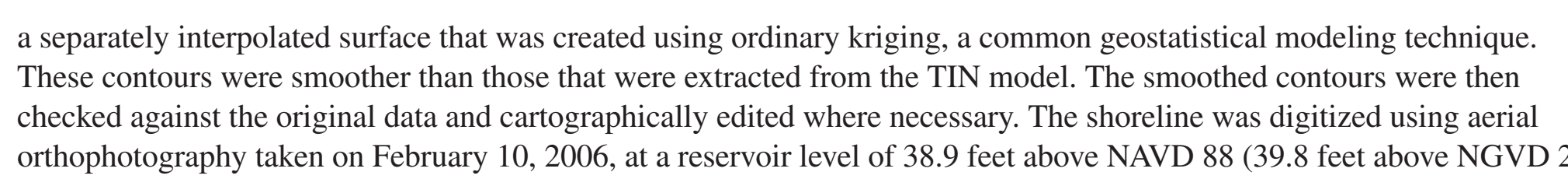

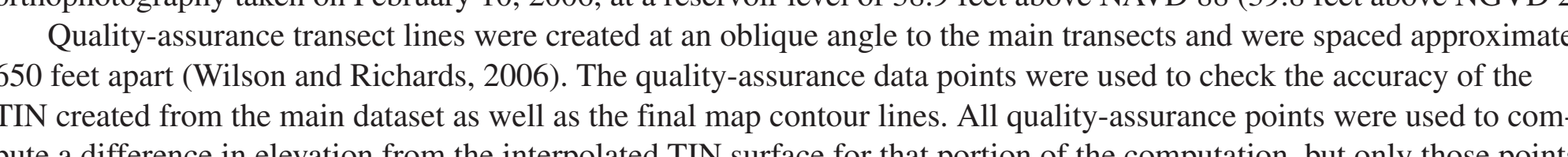

Results

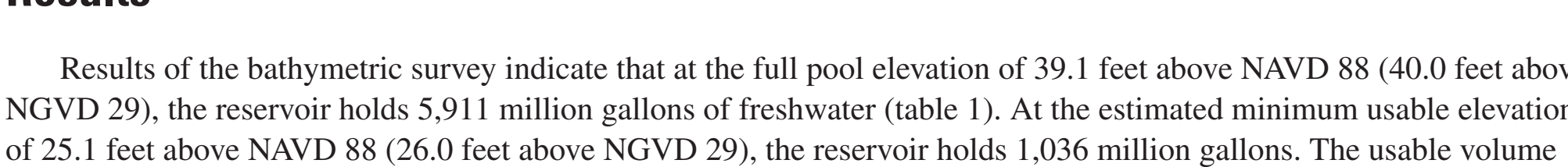

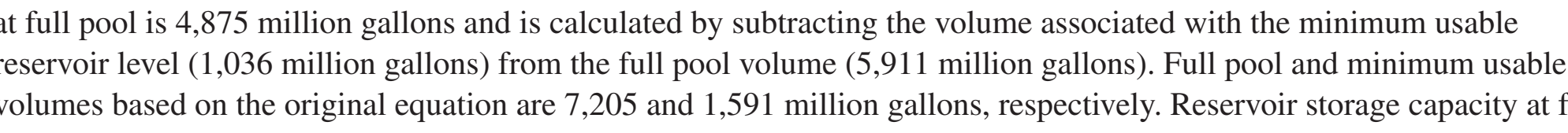

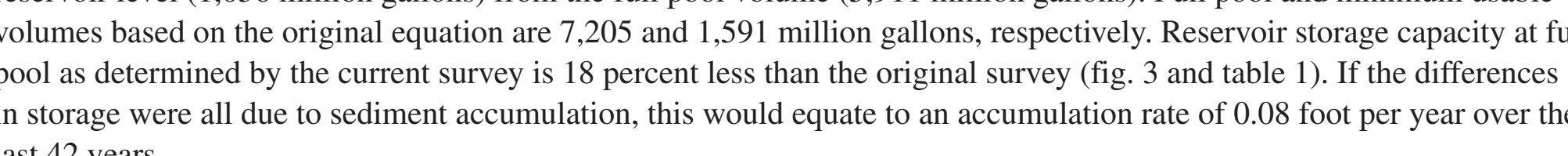

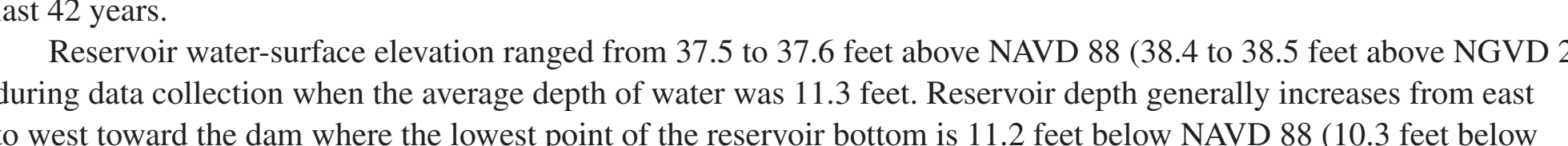

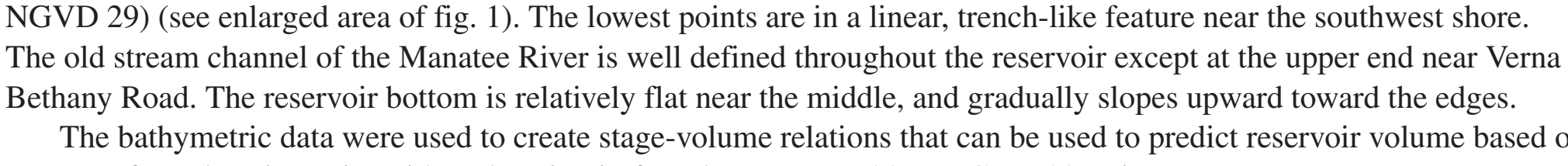

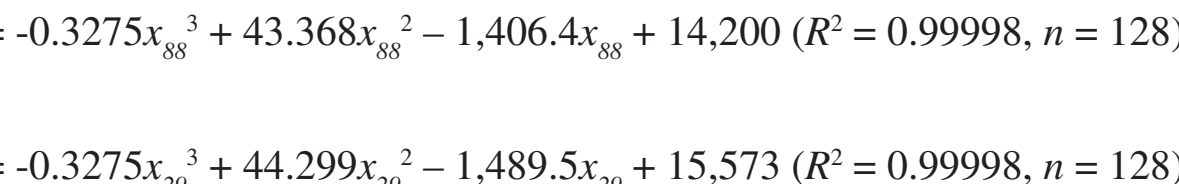

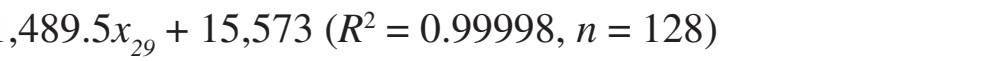

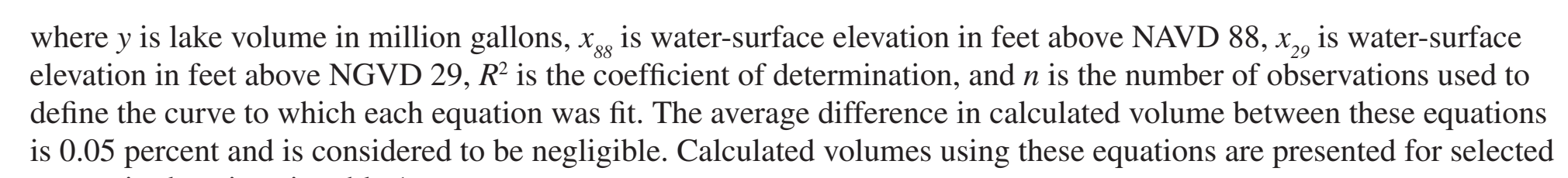

\section{Discussion of Accuracy}

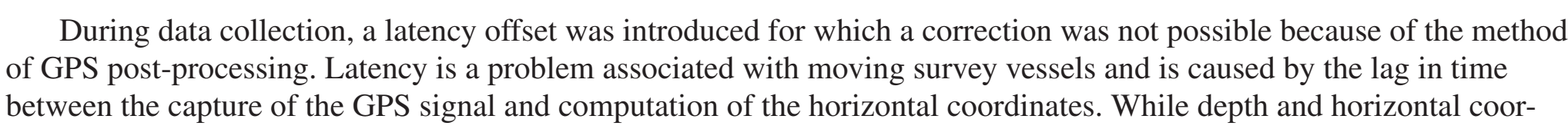

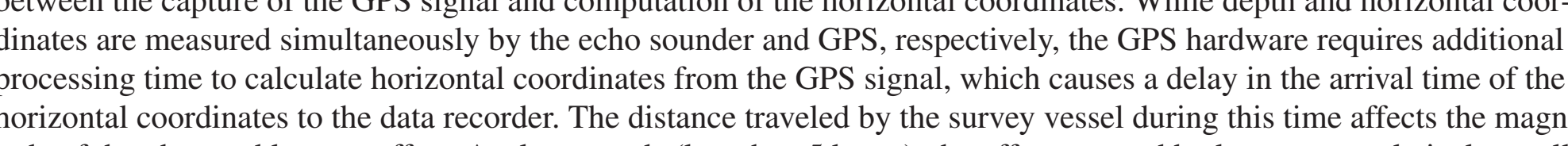

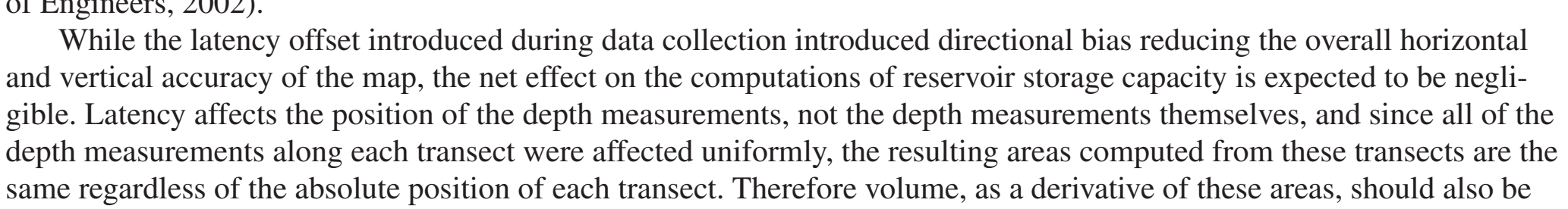

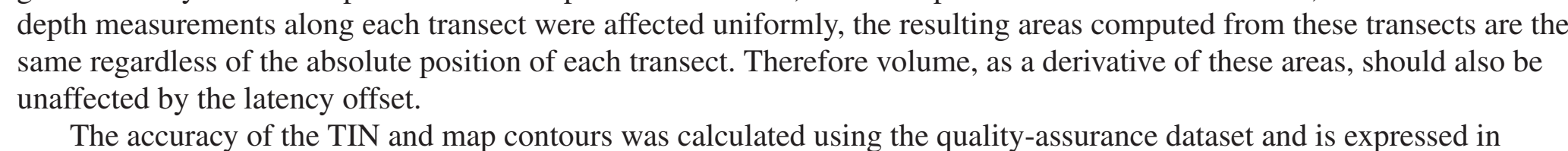

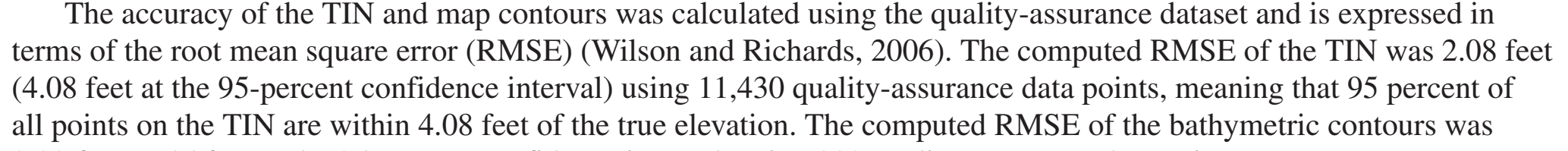

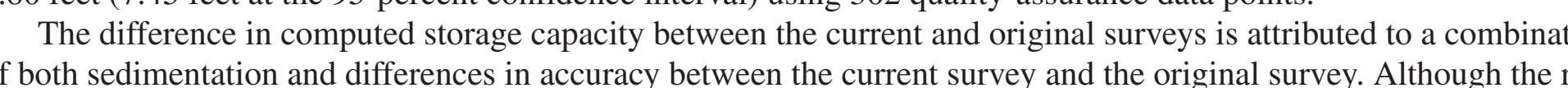

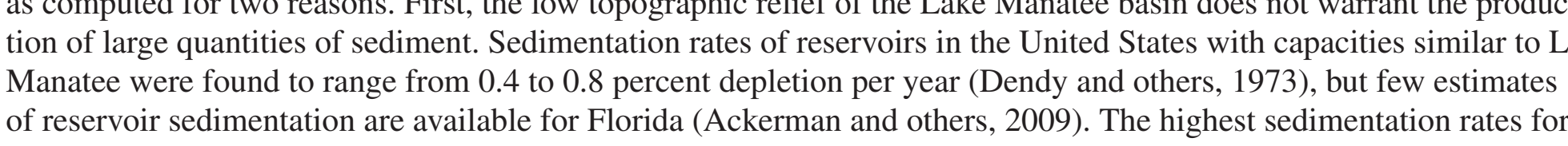

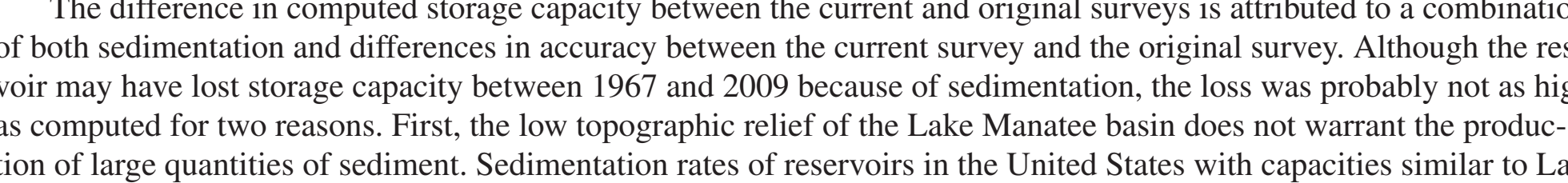

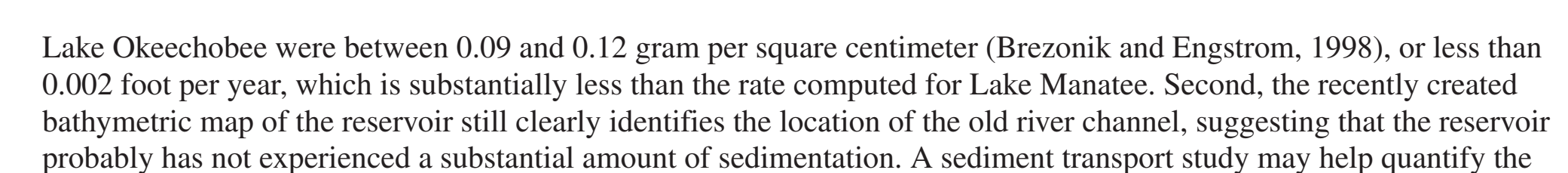

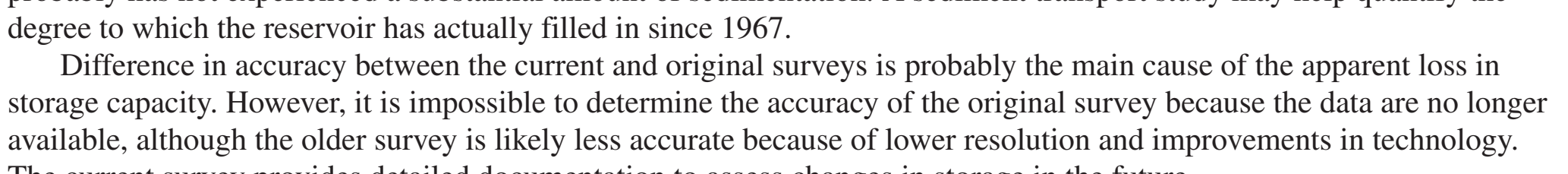
Summary

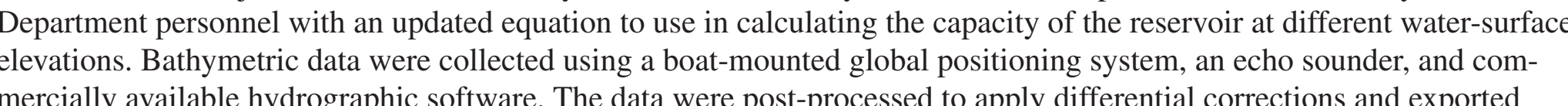

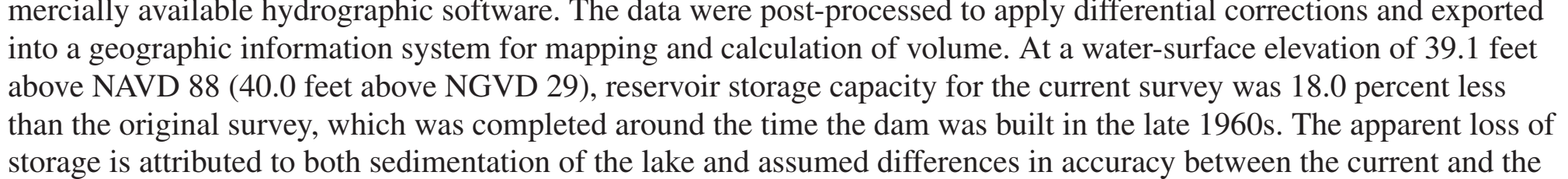
Acknowledgments

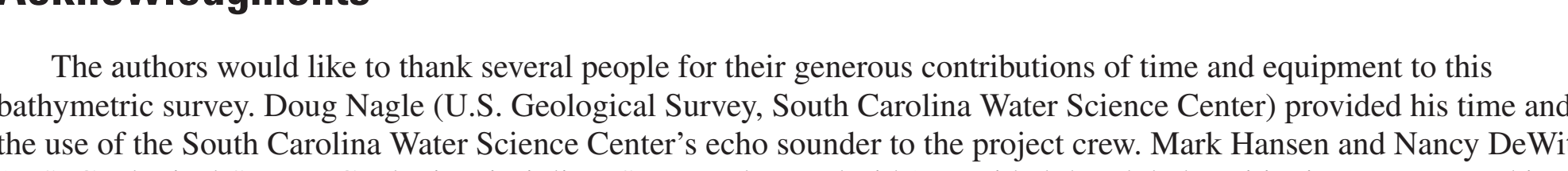

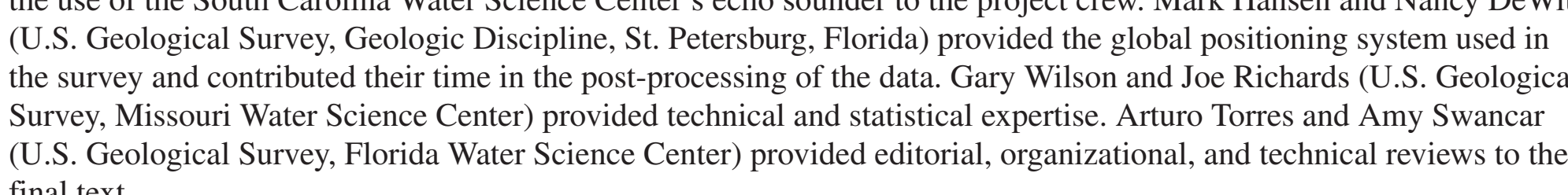

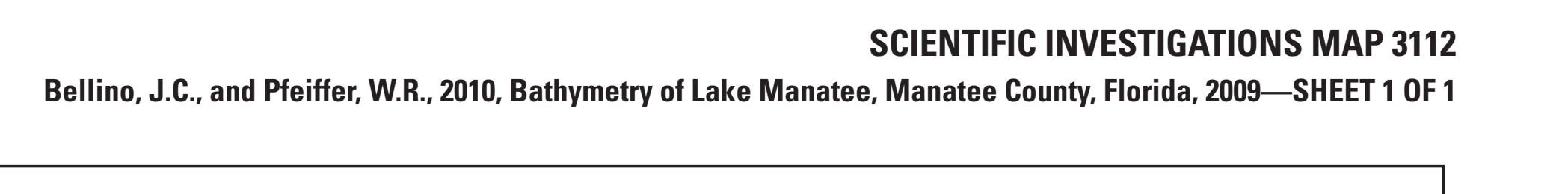

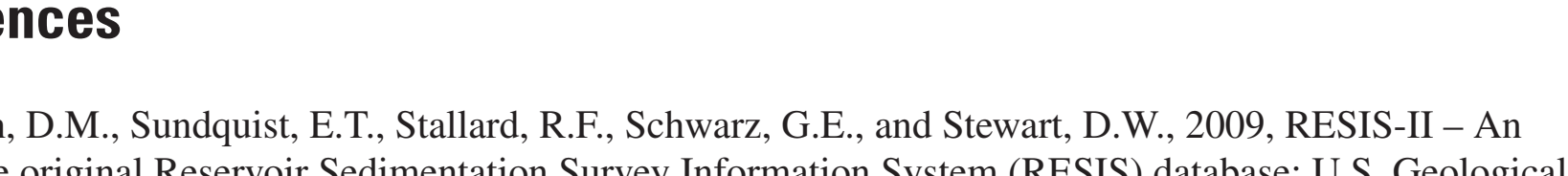

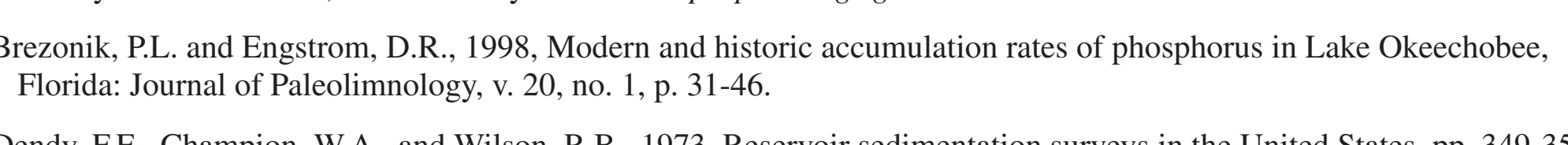

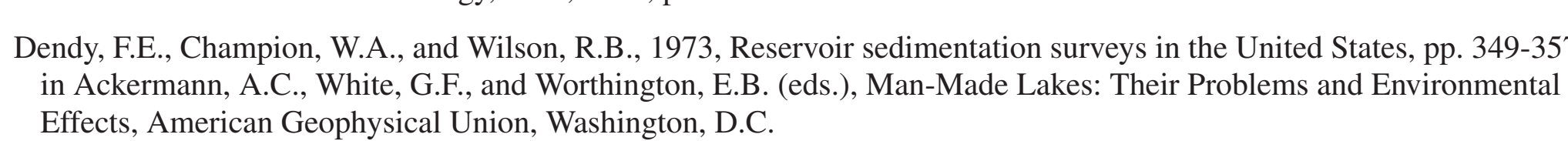

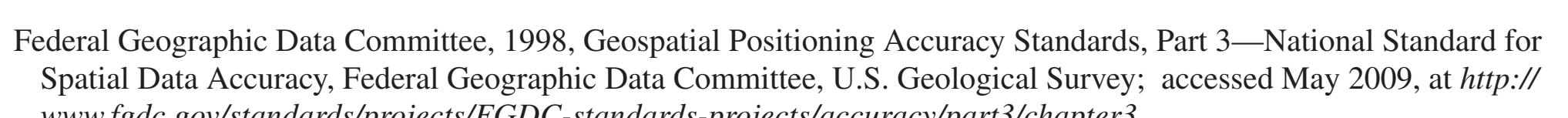

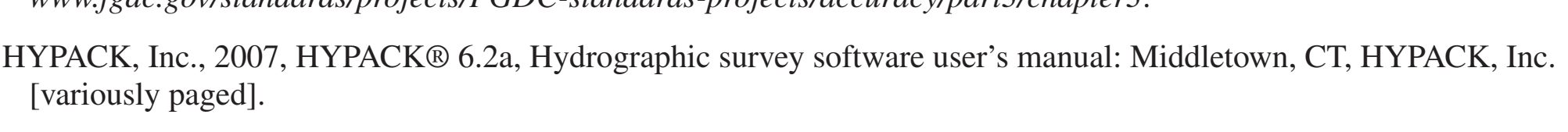

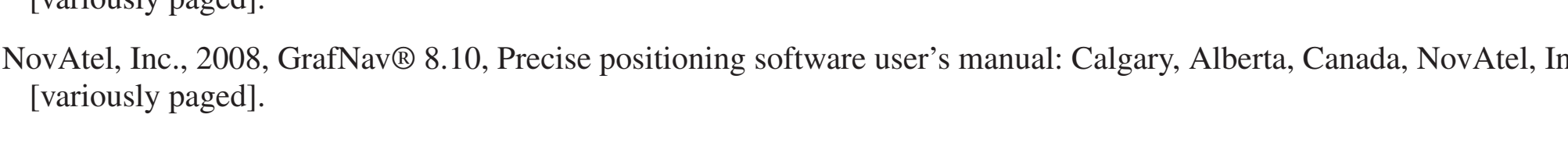

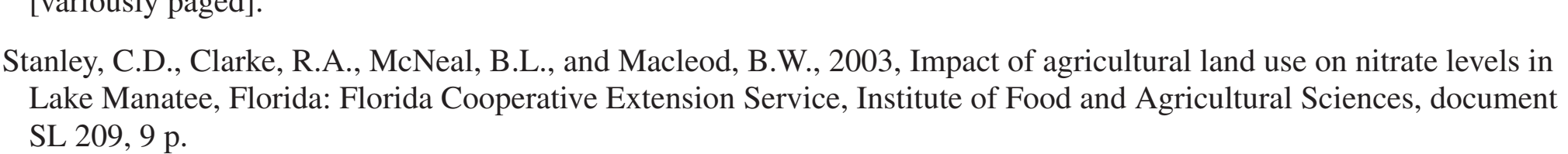

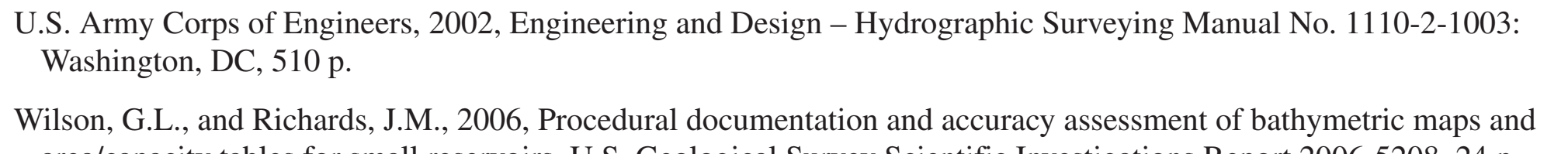

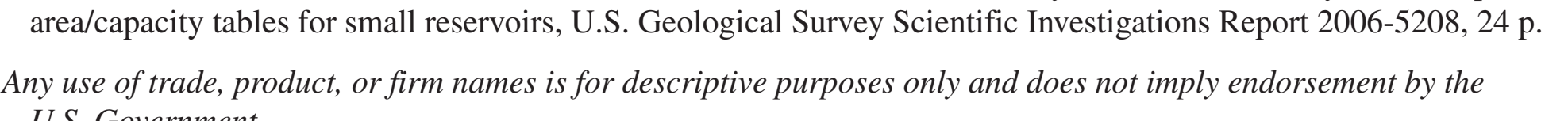

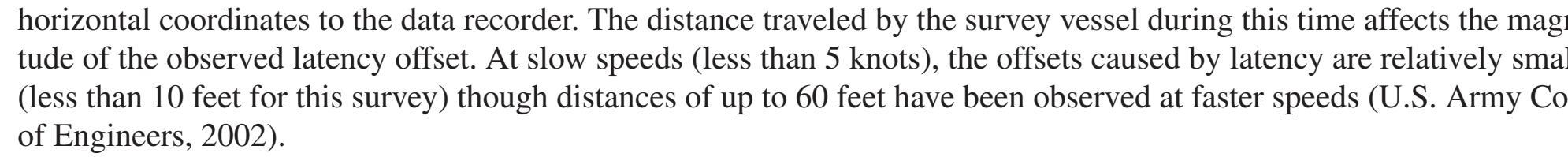

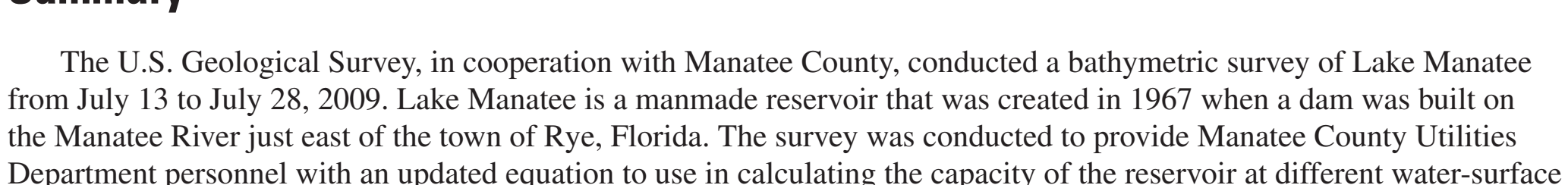
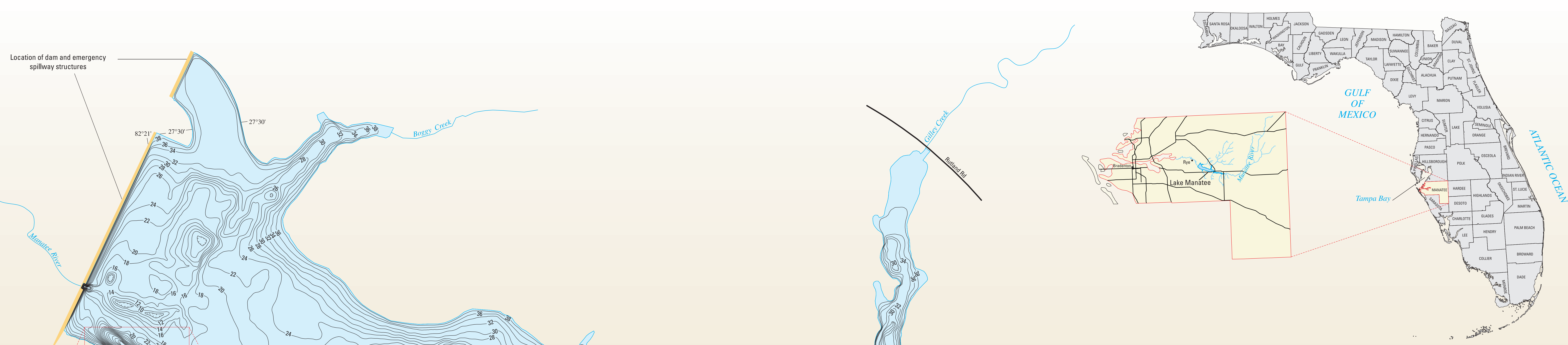
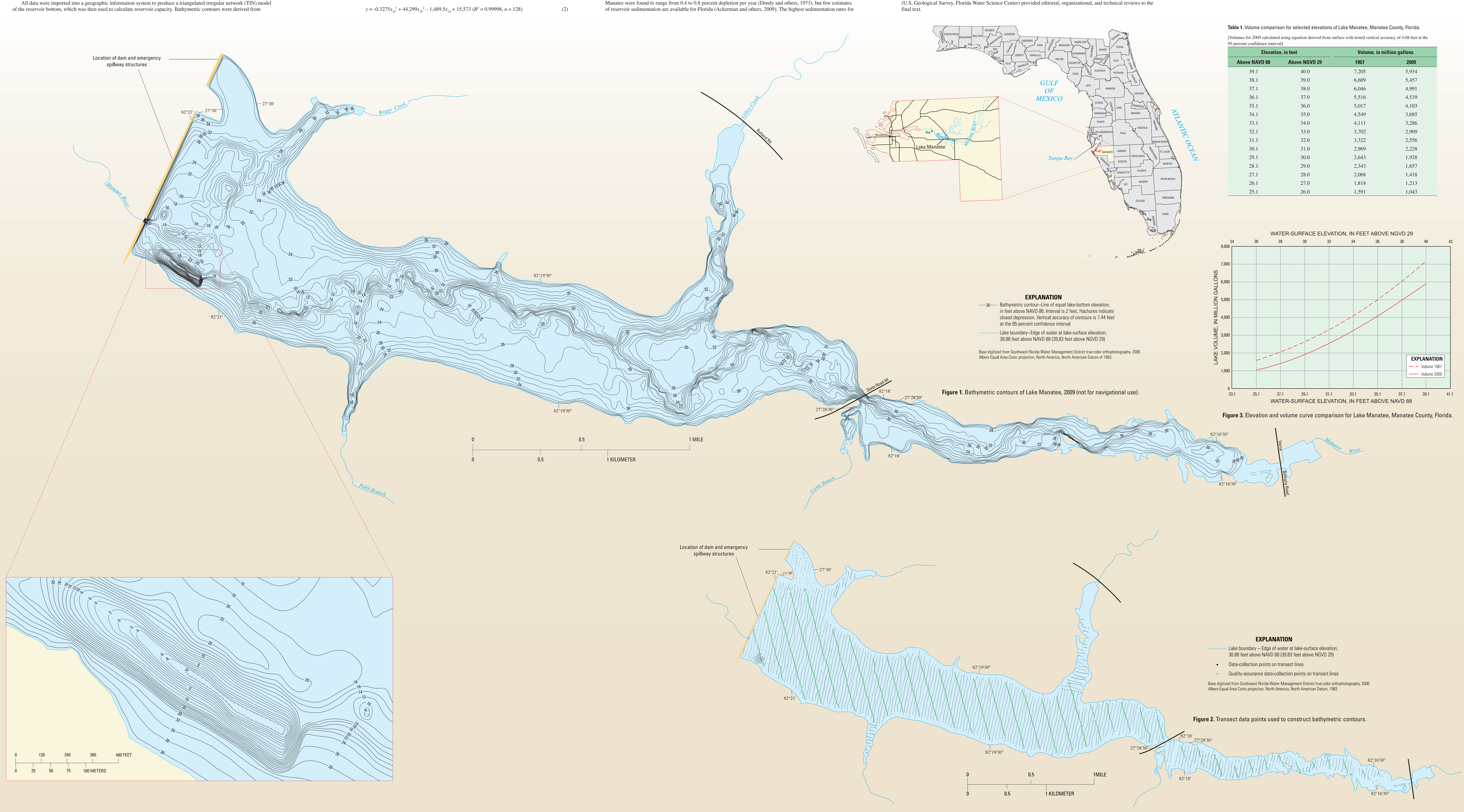